\title{
The Ecosystem Approach as a Frame for SDG 14 Implementation
}

Daniela Diz

Strathclyde Centre for Environmental Law \& Governance, UK

\section{INTRODUCTION}

The ecosystem approach as defined by the UN Convention on Biological Diversity (CBD) Conference of the Parties $(\mathrm{COP})^{1}$ can provide a comprehensive strategy and framework for the implementation of the Sustainable Development Goal (SDG) 14 on the conservation and sustainable use of the oceans, seas and marine resources for sustainable development. This paper argues that by applying the ecosystem approach (EA), States, competent organisations and other relevant actors, would have the opportunity to place the of the health oceans in the centre of environmental conservation and sustainable development, overcoming a siloes approach towards SDGs integration, and as a means for mainstreaming (the conservation and sustainable use of) biodiversity into the implementation of the SDGs. $^{2}$ In doing so, this paper will: (i) recall the often neglected principles of the CBD ecosystem approach, as well as the Food and Agriculture Organization of the UN (FAO) ecosystem approach to fisheries (EAF); (ii) discuss the alignment between SDG 14 and the ecosystem approach; and (iii) explore ways for mainstreaming biodiversity into a select number of SDG 14 targets (SDG 14.1-14.5); before providing concluding remarks on the role of the ecosystem approach as an integrative principle for coherent oceans governance in the context of the SDG 14.

It must be recognised that for the ecosystem approach to be truly implemented, emerging/imminent issues, such as deep seabed mining, need to be properly considered. However, it was beyond the scope of the current work to address deep seabed mining considerations specifically, nor its draft exploitation regulations. Nonetheless, some of the cross-cutting issues addressed herein apply to deep seabed mining

\footnotetext{
${ }^{1}$ CBD Decision V/6 (2000), VII/11 (2004).

${ }^{2}$ As per CBD Decision XIII/3 (2016).
} 
(e.g. anthropogenic underwater noise, biodiversity-inclusive impact assessments, marine spatial planning).

\section{THE ECOSYSTEM APPROACH AS REFLECTED IN KEY INSTRUMENTS}

Under the $\mathrm{CBD}$, the ecosystem approach is considered to be a priority framework for addressing the three objectives of the Convention, ${ }^{3}$ namely conservation of biodiversity, the sustainable use of its components, and the equitable sharing of benefits arising from the utilization of genetic resources. ${ }^{4}$ Furthermore, EA has been defined as "a strategy for the integrated management of land, water and living resources that promotes conservation and sustainable use in an equitable way." ${ }^{5}$ Implementation guidelines for the twelve principles of the Ecosystem Approach, previously endorsed by COP in 2000, form part of a 2004 CBD Decision. ${ }^{6}$

Even though the EA twelve principles support integration and cross-sectoral management, they also align well with sectoral modalities of the ecosystem approach, such as the ecosystem approach to fisheries. $^{7}$

\section{CBD EA Principles}

\section{FAO EAF Principles}

1. The objectives of management of land, 1. Avoiding overfishing water and living resources are a matter of societal choice

2. Management should be decentralized to the lowest appropriate level

3. Ecosystem managers should consider the effects (actual or potential) of their activities on adjacent and other ecosystems

\footnotetext{
${ }^{3}$ As per CBD Decision VII/11 (2004), para 2.

${ }^{4}$ CBD, Art. 1.

${ }^{5}$ CBD Decision VII/7 (2004), Annex I, para 1.

${ }^{6}$ See figure 1 for CBD 12 EA Principles and FAO EAF principles.

${ }^{7}$ See FAO Fisheries Department. The ecosystem approach to fisheries. FAO Technical Guidelines for Responsible Fisheries. No. 4, Suppl. 2. Rome, FAO. 2003. 112 p.
} 
4. Recognizing potential gains from management, there is usually a need to understand and manage the ecosystem in an economic context. Any such ecosystemmanagement programme should: (a) Reduce those market distortions that adversely affect biological diversity; (b) Align incentives to promote biodiversity conservation and sustainable use; (c) Internalize costs and benefits in the given ecosystem to the extent feasible

5. Conservation of ecosystem structure and functioning, in order to maintain ecosystem services, should be a priority target of the ecosystem approach

6. Ecosystems must be managed within the limits of their functioning

7. The ecosystem approach should be undertaken at the appropriate spatial and temporal scales

8. Recognizing the varying temporal scales and lag-effects that characterize ecosystem processes, objectives for ecosystem management should be set for the long term 9. Management must recognize that change is inevitable

10. The ecosystem approach should seek the appropriate balance between, and integration of, conservation and use of biological diversity

11. The ecosystem approach should consider all forms of relevant information, including scientific and indigenous and local knowledge, innovations and practices

12. The ecosystem approach should involve all relevant sectors of society and scientific disciplines
4. Considering species interactions

5. Ensuring compatibility

6. Applying the precautionary approach

7. Improving human well-being and equity

8. Allocating user rights

9. Promoting sectoral integration

10. Broadening stakeholders' participation

11. Maintaining ecosystem integrity

Figure 1: CBD EA Principles and FAO EAF Principles.

The FAO Technical Guidelines on EAF states that EAF is a means for implementing many of the provisions of the Code of Conduct for Responsible Fisheries and for achieving sustainable fisheries. It goes even further in linking EAF with sustainable development, noting EAF as "(...) a means to implement sustainable development concepts into fisheries by addressing both human and ecological 
well-being." ${ }^{8}$ The following cluster of EAF principles contained in the EAF Guidelines support this notion:

a) Management units should be based on ecologically meaningful boundaries;

b) Fisheries should be managed in a way that limits their impacts on the ecosystem;

c) Ecological relationships should be maintained and rebuilt;

d) Management measures should be compatible with the entire distribution of the stocks;

e) The precautionary approach is a component of EAF given lack of full scientific knowledge related to ecosystems and their functions;

f) Governance should ensure both human and ecosystem well-being.

The link between sustainable development and the ecosystem approach for both ecological and human well-being has been further elaborated in the outcome document of the UN Conference on Sustainable Development, The Future We Want, under which, UN Member States committed themselves to:

"(...) protect, and restore, the health, productivity and resilience of oceans and marine ecosystems, to maintain their biodiversity, enabling their conservation and sustainable use for present and future generations, and to effectively apply an ecosystem approach and the precautionary approach in the management, in accordance with international law, of activities having an impact on the marine environment, to deliver on all three dimensions of sustainable development."

It is, thus, logical that the SDGs, adopted three years later would embrace a similar notion, as discussed in the following section.

SDG 14 AND ECOSYSTEM APPROACH ALIGNMENTS

\footnotetext{
${ }^{8}$ FAO EAF Guidelines (2003), at 6.

${ }^{9}$ UN General Assembly Resolution 66/288 (2012), para 158.
} 
Despite the link between sustainable development and the ecosystem approach contained in the Future We Want, none of SDG 14 targets explicitly refers to the ecosystem approach. Nonetheless, the 2017 UN Ocean Conference outcome document, Our Ocean, Our Future: Call for Action - a declaration endorsed by the UN General Assembly, ${ }^{10}$ provided further clarity to the interpretation of SDG 14 targets and their alignment with the ecosystem approach. For instance, the Declaration stresses "the need for an integrated, interdisciplinary and cross-sectoral approach, as well as enhanced cooperation, coordination and policy coherence, at all levels"11 - something that is intrinsic to the application of the ecosystem approach as per the CBD and several other instruments. The Declaration also called for "the use of effective and appropriate area-based management tools, including marine protected areas and other integrated, cross-sectoral approaches, including marine spatial planning and integrated coastal zone management, based on best available science, as well as stakeholder engagement and applying the precautionary and ecosystem approaches". ${ }^{12}$ Spatial management and cross-sectoral management are essential components of EA, as seen in the previous section.

The ecosystem approach was also explicitly called for in the Declaration with respect to its role in the implementation of SDG 14.4 on sustainable fisheries. ${ }^{13}$ Furthermore, the application of ecosystembased management has been spelled out as an indicator for achieving SDG 14.2 (healthy and productive oceans) in States' exclusive economic zones (EEZs). It is not clear why this indicator left behind areas beyond national jurisdiction, since these areas play an important role in securing health, productivity and resilience across all ocean basins, and the approach has already been (directly or indirectly) integrated in global treaties applicable to ABNJ, such as UNCLOS, the UN Fish Stocks Agreement (UNFSA), CBD, the Convention on Conservation of Migratory Species of Wild Animals (CMS), and policy instruments such as the FAO Code of Conduct for Responsible Fisheries.

\footnotetext{
${ }^{10}$ UN General Assembly Resolution 71/312 (2017).

${ }^{11}$ UNGA Resolution 71/312 (2017), para 8.

${ }^{12}$ UNGA Resolution 71/312 (2017), para 13 (j).

${ }^{13}$ UNGA Resolution 71/312 (2017), para 13 (1).
} 
It has been argued that the EA's elusive nature still challenges its coherent implementation. ${ }^{14}$ The ecosystem approach has been contested by scholars and practitioners for constituting an over-promise of guaranteed win-win results of competing interests related to conservation vs natural resource exploitation. ${ }^{15}$ It is important to also recall that while convergence (of policy, of interpretation, and of implementation) is an EA aim, divergence of views, leading to compromises and trade-offs, is also expected under the Ecosystem Approach. ${ }^{16}$ By shedding light on the hidden trade-offs around ecosystem services flows and among stakeholders, decision-makers are better equipped to perform their tasks in a fairer, more equitable and sustainable manner. ${ }^{17}$ Ecosystem services methods have assist in identifying those trade-offs, which if left unaddressed, can lead to poverty traps of the most vulnerable, potentially undermining SDGs on poverty, hunger, malnutrition, education, and so many others. Daw et al (2011) provides examples of trade-offs within and across small-scale fisheries groups, under which light was shed on wellbeing aspects of marginalised or under-represented groups (e.g. women). ${ }^{18}$ The use of ecosystem services methods to evaluate such trade-offs for a fairer society is embraced by the EA improved integrated governance coherence. ${ }^{19}$

${ }^{14}$ V de Lucia, "Compelling Narratives and Complex Genealogies: The Ecosystem Approach in International Environmental Law” (2015) 27 Journal of Environmental Law 91-117. Doi: 10.1093/jel/equ031.

15 Ibid.

${ }^{16}$ D Diz, E Morgera, "Insights for Sustainable Small-scale Fisheries” in K Schreckenberg, G Mace, M Poudyal (Eds), Ecosystem Services and Poverty Alleviation: Trade-offs and Governance (Routledge, 2018).

${ }^{17}$ D Diz, E Morgera, "Insights for Sustainable Small-scale Fisheries” in K Schreckenberg, G Mace, M Poudyal (Eds), Ecosystem Services and Poverty Alleviation: Trade-offs and Governance (Routledge, 2018).

${ }^{18}$ T Daw, K Brown, S Rosendo, et al, “Applying the Ecosystem Services Concept to Poverty Alleviation: The Need to Disaggregate Human Well-being” (2011) 38 Environmental Conservation 370-379. See also T Daw, S Coulthard, W Cheung et al "Evaluating Taboo Trade-offs in Ecosystem Services and Human Well-being" (2015) 112 Proceedings of the National Academy of Sciences 6949-6954.

${ }^{19}$ CBD Decisions V/6 (2000) and VII/11 (2004), principles 1 and 2. The rationale for Principle 1 highlights the importance of all stakeholders to be involved in the process, by stating that: "Different sectors of society view ecosystems in terms of their own economic, cultural and societal needs. Indigenous peoples and other local communities living on the land are important stakeholders and their rights and interests should be recognized. Both cultural and biological diversity are central components of the ecosystem approach, and management should take this into account. Societal choices should be expressed as clearly as possible. Ecosystems should be managed for their intrinsic values and for the tangible or intangible benefits for humans, in a fair and equitable 
The need for governance coherence has been a core feature of the UN Convention on the Law of the Sea, which in its preamble notes that " ... the problems of ocean space are closely interrelated and need to be considered as a whole". ${ }^{20}$ An ecosystem approach, therefore, seems to be the appropriate route to achieve governance coherence. SDG 14.c, ${ }^{21}$ recognises that UNCLOS provides the legal framework for the conservation and sustainable use of oceans and their resources. In this connection, global and regional standards incorporated by reference under UNCLOS play an important role in achieving SDG 14 as they contribute to a dynamic governance regime. The next section will address how some of the existing standards and guidance can contribute to a coherent implementation of the SDG 14.

\section{MAINSTREAMING BIODIVERSITY INTO SDG 14 FOR GOVERNANCE COHERENCE}

Conservation of 'biodiversity' and its sustainable use is not expressly mentioned in UNCLOS, but the incorporation of such obligations is implied in a number of its provisions. ${ }^{22}$ Furthermore, as mentioned in the previous section, as part of its evolutionary nature, UNCLOS incorporates by reference generally agreed global, regional or sub-regional minimum standards with respect to, inter alia, the adoption of conservation and management fisheries measures in the exclusive economic zone ${ }^{23}$ and on the high

way." (CBD Decision VII/11, table 1, principle 1). In addition, the implementing guidelines for Principle 4 recommend the application of ecosystem services valuation methodologies.

${ }^{20} \mathrm{UNCLOS}, 3^{\text {rd }}$ preambular paragraph.

21 "Enhance the conservation and sustainable use of oceans and their resources by implementing international law as reflected in UNCLOS, which provides the legal framework for the conservation and sustainable use of oceans and their resources, as recalled in paragraph 158 of The Future We Want.” SDG 14.c.

${ }^{22}$ For instance, Part XII on the protection and preservation of the marine environment (which is applicable to all maritime zones), particularly, Arts. 192, 194 (5) more broadly, as well as Parts V on the Exclusive Economic Zone and VII on the High Seas.

${ }^{23}$ UNCLOS, Art. 61 (3). 
seas, ${ }^{24}$ and pollution from land-based sources, ${ }^{25}$ from seabed activities, ${ }^{26}$ from dumping, ${ }^{27}$ from vessels, ${ }^{28}$ and from or through the atmosphere. ${ }^{29}$

Furthermore, the mutual supportiveness between UNCLOS and the CBD with respect to the marine environment is explicitly found in Article 22 of the $\mathrm{CBD},{ }^{30}$ which states that Parties shall implement the Convention consistently with the rights and obligations of States under UNCLOS. In this connection, CBD also notes that the Convention shall not affect the rights and obligations of Parties under existing international agreements, unless the exercise of these would cause a serious damage or threat to biodiversity. ${ }^{31}$ CBD parties should also mainstream biodiversity into productive sectors by integrating "consideration of the conservation and sustainable use of biological resources into national decision-making". ${ }^{32}$ Aligned to this notion, CBD Decision XIII/3 (2016) called for mainstreaming biodiversity into productive sectors including tourism and fisheries, and recalled the respective CBD Decisions on EA, which had recommended the application of the EA in all sectors with potential impacts on biodiversity and ecosystems. The same decision urged Parties to mainstream biodiversity in the implementation of all relevant SDGs, including through the implantation of the Aichi Biodiversity Targets. ${ }^{33}$ It is important to note that the notion of "mainstreaming biodiversity" is aligned with CBD Art. 6(b), which requires Parties to integrate not only conservation, but also the sustainable use of

\footnotetext{
${ }^{24}$ UNCLOS, Art. 119 (1) (a).

${ }^{25}$ UNCLOS, Art. 207 (1).

${ }^{26}$ UNCLOS, Art. 208 (3).

${ }^{27}$ UNCLOS, Art. 210 (4).

${ }^{28}$ UNCLOS, Art. 211 (2).

${ }^{29}$ UNCLOS, Art. $212(1)$.

${ }^{30}$ James Harrison, "Saving the Oceans through Law: The International Legal Framework for the Protection of the Marine Environment” (OUP, 2017).

${ }^{31}$ CBD, Art. 22 (1).

${ }^{32}$ CBD Art 10 (a).

${ }^{33}$ CBD Decision XIII/3, para 14.
} 
biodiversity into relevant sectoral or cross-sectoral plans, programmes and policies. ${ }^{34}$ The following section will build on relevant CBD COP (and other bodies) deliberations, and focus on some of the avenues for achieving this mainstreaming aim with respect to SDGs 14.4 (sustainable fisheries), 14.1 (marine pollution), SDG 14.2 (healthy, productive and resilient marine ecosystems) and 14.5 (marine protected areas) in the context of an ecosystem approach.

\section{Mainstreaming Biodiversity into Fisheries (and respective SDG 14.4)}

With respect to fisheries standards and international obligations supplementary to UNCLOS, it is important to recall that the UN Fish Stocks Agreement, in its Art. 5 (g), which is applicable in areas within and beyond national jurisdiction, ${ }^{35}$ obliges coastal states and states fishing on the high seas to protect biodiversity in order to conserve and manage straddling fish stocks and highly migratory fish stocks. Similar provisions are contained in several FAO instruments, including the Code of Conduct for Responsible Fisheries and its International Plans of Action, and the FAO International Guidelines for the Management of Deep-sea Fisheries in the High Seas (FAO Deep-sea Fisheries Guidelines), as well in UN General Assembly Resolutions on Sustainable Fisheries. Furthermore, the CBD Aichi Biodiversity Target $6^{36}$ (sustainable fisheries), places "ecosystem-based approaches" in the centre of the target as a means to, by 2020: accomplish sustainability; avoid overfishing; enable the adoption of recovery plans; avoid significant adverse impacts (SAIs) on threatened species and vulnerable ecosystems; avoid fishing impacts on stocks and species; and ecosystems are within safe ecological limits. These EAF elements contained in Aichi Target 6, reflect minimum standards for biodiversity mainstreaming into fisheries as contained in several existing instruments.

\footnotetext{
${ }^{34}$ See CBD Decision XIII/3, first preambular para.

35 See UNFSA, Art. 3 (2).

36 "By 2020 all fish and invertebrate stocks and aquatic plants are managed and harvested sustainably, legally and applying ecosystem based approaches, so that overfishing is avoided, recovery plans and measures are in place for all depleted species, fisheries have no significant adverse impacts on threatened species and vulnerable ecosystems and the impacts of fisheries on stocks, species and ecosystems are within safe ecological limits." CBD Decision, X/2, Aichi Biodiversity Target 6.
} 
Kenny et al (2018) discuss methodologies that assist in the implementation of these EAF elements towards the achievement of SDG 14.4, ${ }^{37}$ even in data limited contexts, and highlight the importance of identifying ecologically meaningful management units as the first step of the assessment. Productivity of the ecosystem in question can be analysed in each biogeographic unit and ecosystem-level total allowable catches can then be set based on a precautionary calculation of ecosystem-level reference points that supplements individual stock assessments, and portraying a more comprehensive picture of the ecosystem composition, trophic interactions, and productivity capacity. ${ }^{38}$ The need to determine prey availability thresholds for certain functional groups is illustrated by Cury et al (2011) in a landmark paper that concluded that approximately one-third of the maximum prey biomass is needed to sustain seabird productivity over the long term. ${ }^{39}$

Habitat mapping (e.g. vulnerable marine ecosystems), environmental impact assessments (EIAs) and risk assessments also play important roles in EAF. ${ }^{40}$ Criteria for bottom fishing EIAs are contained in the FAO Deep-sea Guidelines. ${ }^{41}$ Methodologies that facilitate such assessments even in data-limited contexts $^{42}$ can be a significant contribution to the universal implementation of SDG 14.4 (sustainable fisheries), SDG 14.2 (more resilient ecosystems), as well as Aichi Biodiversity Target 6 (sustainable fisheries), hence also fulfilling respective States obligations under UNCLOS, the Fish Stocks

\footnotetext{
${ }^{37}$ SDG 14.4. reads: "By 2020, effectively regulate harvesting and end overfishing, illegal, unreported and unregulated fishing and destructive fishing practices and implement science-based management plans, in order to restore fish stocks in the shortest time feasible, at least to levels that can produce maximum sustainable yield as determined by their biological characteristics."

${ }^{38}$ A Kenny, N Campbell, M Koen-Alonso, P Pepin, D Diz, "Delivering Sustainable Fisheries through Adoption of a Risk-based Framework as Part of an Ecosystem Approach to Fisheries Management" (2018) 93 Marine Policy 232-240.

${ }^{39}$ PM Cury, IL Boyd, S Bonhommeau, et al "Global Seabird Response to Forage Fish Depletion - One-third for the Birds” (2011) 334 Science 1703-1706.

${ }^{40}$ A Kenny, N Campbell, M Koen-Alonso, P Pepin, D Diz, "Delivering Sustainable Fisheries through Adoption of a Risk-based Framework as Part of an Ecosystem Approach to Fisheries Management" (2018) 93 Marine Policy 232-240.

${ }^{41}$ FAO Deep-sea Fisheries Guidelines, para 47.

${ }^{42}$ See Kenny et al (2018).
} 
Agreement, and a number of other related international treaties, referred to above. In cases of scientific uncertainty, application of the precautionary approach is required ${ }^{43}$ With respect to bottom fishing, this can be achieved through the adoption of precautionary conservation and management measures to avoid SAIs. In areas where vulnerable marine ecosystems have been designated, are known or likely to occur based on habitat suitability models, and other techniques, such areas should be closed to deep-sea fisheries until appropriate conservation and management measures have been adopted to prevent SAIs on VMEs and to ensure long-term conservation and sustainable use of deep-sea stocks. ${ }^{44}$

All of these instruments provide sound guidance to the implementation of SDG 14.2 (productive and healthy ecosystems) from a fisheries perspective, and 14.4 (sustainable fisheries). The work conducted by the Northwest Atlantic Fisheries Organization (NAFO) scientists under the Scientific Council's Working Group on Ecosystem Science and Assessment (WGESA) on the development of the Ecosystem Approach to Fisheries Roadmap should be highlighted here as a particular example of best practice and use of best-available science concerning EAF. The Roadmap and subsequent activities of the group includes: the development of ecosystem-level catch ceilings, assessment of ecosystem-units productivity potential, incorporation of habitat and marine biodiversity assessments for identification of VMEs, risk assessments, among others. ${ }^{45}$ Nevertheless, the Roadmap would benefit from its full implementation for the achievement of the Aichi Biodiversity Target 6 and SDG 14.4 in the region by 2020. The NAFO 2018 Performance Review Panel has indeed recommended ensuring the practical application of the ecosystem approach. ${ }^{46}$

\footnotetext{
${ }^{43}$ UNFSA, Art. 6; FAO Deep-sea Fisheries Guidelines, paras 12, 20, 22, 65, 74, 76, FAO Code of Conduct, paras 6.5 and 7.5 .

${ }^{44}$ FAO Deep-sea Guidelines, para 66.

${ }^{45}$ Kenny et al (2018).

${ }^{46}$ B Boechat de Almeida, MJ Willing, P Degnbol, J Baird, F Candela Castillo, T L $\emptyset$ bach, NAFO Performance Review Panel Report 2018 (NAFO, 2018).
} 


\section{Addressing marine pollution impacts on biodiversity (in the context of SDG 14.1)}

With respect to marine pollution from various sources, especially from land-based sources, which is the main focus of SDG 14.1, ${ }^{47}$ a holistic approach for tackling the issue is also needed. Furthermore, the cumulative impacts of marine debris with other stressors on biodiversity, species and ecosystems should also be taken into account in decision-making. For example, while plastic is chemically inert, plastic can absorb organic pollutants in high concentrations. Microplastics can be retained in tissues of marine species and humans at the top of the food chain, and associated-pollutants might be released upon ingestion. ${ }^{48}$ Entanglement of marine species is also a big threat to biodiversity and species, while floating plastic litter can transport invasive species - constituting another threat to endemic biodiversity. UNEP has estimated that $80 \%$ of marine debris and plastics are from land-based sources and that 90 $95 \%$ of marine pollution is composed of plastic. ${ }^{49}$

UNCLOS, through its Article 192 imposes an obligation on States to protect and preserve the marine environment, with Article 207 (1) binding States to adopt laws and regulations to prevent, reduce and control pollution of the marine environment from land-based sources, taking into account internationally agreed standards and best practices. This language therefore allows for the incorporation by reference of policy instruments and guidance such as those contained in CBD Decisions on marine debris and relevant UN environment Assembly (UNEA) resolutions. Furthermore, Article 213 of UNCLOS mandates that States not only adopt laws and regulations, but also enforce these, while taking measures to adopt international standards.

\footnotetext{
47 "By 2025, prevent and significantly reduce marine pollution of all kinds, in particular from land-based activities, including marine debris and nutrient pollution" SDG 14.1.

${ }^{48}$ Cole, Matthew, et al. (2011) "Microplastics as contaminants in the marine environment: a review" 62(12) Marine pollution bulletin 2588-2597.

${ }^{49}$ UNEP (2016). Marine plastic debris and microplastics - Global lessons and research to inspire action and guide policy change. United Nations Environment Programme, Nairobi.
} 
Several other international instruments ${ }^{50}$ address marine debris in some form and both from land-based or sea-based sources, providing standards and further guidance to states in implementing their obligations under UNCLOS. However, given the fragmented nature of the current legal regime governing marine debris, efforts to enhance cooperation and coordination among different international fora is key for the comprehensive implementation of respective measures. In this connection, it is important to note the efforts by UN Environment Assembly (UNEA) to address the issue by recognizing the need for an urgent global response taking into account a product life-cycle approach. ${ }^{51}$ Therefore, the relationship between SDG 14.1 (on preventing and reducing marine pollution, in particular marine debris from land-based sources by 2025) and SDGs 12.1 and 12.5 on sustainable production and consumption is of utmost importance, since production life-cycle is at the heart of the problem.

Furthermore, CBD Decision XIII/10 on marine debris, urged States to prevent and mitigate the potential adverse impacts of marine debris, and to take into account the CBD Voluntary Practical Guidance on Preventing and Mitigating the Impacts of Marine Debris on Marine and Coastal Biodiversity and Habitats. ${ }^{52}$ Despite its voluntary nature, the CBD guidance can be interpreted as internationally agreed standards under UNCLOS Article 207 cited above.

SDG 14.1 (marine pollution) can also cover anthropogenic underwater noise, which is another type of pollution of the marine environment ${ }^{53}$ that threatens marine mammals, and several other marine species

\footnotetext{
${ }^{50}$ These include, inter alia: the International Convention for the Prevention of Pollution from Ships (MARPOL), Annex V on Prevention of Pollution by Garbage from Ships; the London Convention and its London Protocol; the Basel Convention on the Control of Transboundary Movements of Hazardous Wastes and their Disposal; the Agreement on the Conservation of Albatrosses and Petrels; the Global Programme of Action for the Protection of the Marine Environment from Land-based Activities, and Regional Seas Programmes and Conventions; the Stockholm Convention on Persistent Organic Pollutants; the FAO Code of Conduct for Responsible Fisheries; UN Agreement for the Implementation of the Provisions of the UN Convention on the Law of the Sea of 10 December 1982 relating to the Conservation and Management of Straddling Fish Stocks and Highly Migratory Fish Stocks (Fish Stocks Agreement).

${ }^{51}$ UNEA Resolution 2/11 (2016).

${ }^{52}$ CBD, Decision XIII/10, Annex, Doc CBD/COP/DEC/XIII/10, 10 December 2016.

${ }^{53}$ UNCLOS Art. 1 (4) defines pollution of the marine environment as "the introduction by man, directly or indirectly, of substances or energy into the marine environment, including estuaries, which results or is likely to result in such deleterious effects as harm to living resources and marine life, hazards to human health, hindrance
} 
and ecosystems. Anthropogenic underwater noise has also been the object of deliberations of the CBD and the CMS respective COPs. In 2014, CBD COP encouraged parties and other governments and invited competent organisations to take measures to avoid, minimize and mitigate potential significant adverse impacts of anthropogenic underwater noise. ${ }^{54}$ The recommended measures include: developing and transferring quieter technologies; mapping spatial and temporal distribution of sound; overlaying acoustic mapping with habitat mapping of sound-sensitive species in the context of risk assessments to noise impacts; making use of spatio-temporal knowledge to avoid noise generation in places and times where vulnerable species or populations are present; conducting impact assessments and subsequent monitoring for activities with the potential to cause significant adverse impacts on noise-sensitive species; adopting thresholds to protect sound-sensitive species.

\section{The role of biodiversity-inclusive EIAs \& SEAs to prevent harm to the marine environment}

Environmental Impact Assessments are key tools for the prevention of significant adverse impacts to the marine environment under UNCLOS ${ }^{55}$ and are integral components of the ecosystem approach to management as per the CBD EA strategy. ${ }^{56}$ EIAs are also an enabling tool for the identification of

to marine activities, including fishing and other legitimate uses of the sea, impairment of quality for use of sea water and reduction of amenities". In accordance with such definition, anthropogenic underwater noise, can be interpreted as a type of pollution under UNCLOS. The CMS Conference of the Parties has recognized that "anthropogenic marine noise, depending on source and intensity, is a form of pollution, composed of energy, that may degrade habitat and have adverse effects on marine life ranging from disturbance of communication or group cohesion to injury and mortality”. CMS Resolution 12.14 (2017), second preambular para.

${ }^{54}$ CBD Decision XII/23 (2014), para. 3.

${ }^{55}$ UNCLOS, Arts 204-206.

${ }^{56}$ CBD Decision VII/11, Table 1, Principle 3 ("Ecosystem managers should consider the effects (actual and potential) of their activities on adjacent and other ecosystems"), para 3.3 expressly indicates that EIAs, including SEAs "should be carried out for developments that may have substantial environmental impacts taking into account all the components of biological diversity. These assessments should adequately consider the potential offsite impacts. The results of these assessments, which can also include social impact assessment, should subsequently acted upon. When identifying existing and potential risks or threats to ecosystem, different scales need to be considered." 
measures related to sustainable use of marine biological resources, which avoid or minimise adverse impacts on biodiversity. ${ }^{57}$

Further to CBD decision on anthropogenic underwater noise, the CMS COP has "strongly urge[d] Parties to prevent adverse effects on CMS-listed marine species and their prey by restricting the emission of underwater noise; and where noise cannot be avoided, further urges Parties to develop an appropriate regulatory framework or implement relevant measures to ensure a reduction or mitigation of anthropogenic marine noise" ${ }^{58}$ The resolution, among other things, also urged Parties to ensure that EIAs take full account of underwater noise effects on CMS-listed species and their prey, and to "consider a more holistic ecological approach at a strategic planning stage". 59

To facilitate the implementation of this resolution, Parties also adopted the CMS Family Guidelines on Environmental Impact Assessments for Marine Noise-generating Activities (CMS EIA Guidelines), which should be read in tandem with the Technical Support Information to the CMS EIA Guidelines. ${ }^{60}$ Specific guidance for underwater noise consideration in EIAs and SEAs is important, since scientific modelling exercises are needed for specific contexts and habitats given that sound propagation does not only depend on distance, but also on noise frequencies, water depth, topography, temperature, salinity and other environmental variations. ${ }^{61}$ Furthermore, the CMS EIA Guidelines provides for 'exclusion zones' as areas that are supposed to be designated for the protection of specific species or populations, and therefore, activities and their respective noise should not be propagated into these areas. ${ }^{62}$ The designation of such areas by Costal States and competent organisations are of particular importance for

\footnotetext{
${ }^{57}$ CBD, Art. 10 (b).

${ }^{58}$ CMS Resolution 12.14 (2017), para. 4.

${ }^{59}$ CMS Resolution 12.14 (2017), para 6.

${ }^{60}$ CMS Resolution 12.14 (2017), para 7, and its Annex. See also: < www.cms.int/guidelines/cms-familyguidelines-EIAs-marine-noise $>$ and $<$ https://www.cms.int/sites/default/files/basic page documents/CMSGuidelines-EIA-Marine-Noise_TechnicalSupportInformation_FINAL20170918.pdf> Accessed on 15 July 2018

${ }^{61}$ CMS Resolution 12.14 (2017), Annex, paras 8 and 23.

${ }^{62}$ CMS Resolution 12.14, Annex, para 20.
} 
resident populations. The Guidelines suggest consideration of exclusion zones as part of the EIA noise propagation modelling and as part of subsequent mitigation and monitoring plans for a number of activities, such as military and civil high powered sonar, shipping and vessel traffic, construction works and offshore platforms.

The concern of CMS Parties with not only CMS species, but also with their prey and with the need to assess impacts in a more ecologically holistic manner aligns well with the ecosystem approach. The implementation of CMS EIA Guidelines (along with other relevant frameworks as discussed herein) can contribute towards the achievement of SDGs 14.1 and 14.2 (healthy ecosystems). Furthermore, it can also contribute to SDG 14.5 on marine protected areas, as MPAs could benefit from tailored measures to prevent anthropogenic underwater noise impacts on the species and ecosystems that fall within their management scope.

Complementing the CMS EIA Guidelines, and with a more habitat-oriented focus, the CBD Voluntary EIA/SEA Guidelines ${ }^{63}$ provides further guidance on how to integrate marine and coastal biodiversity considerations into EIAs and SEAs.

The CBD Guidelines recommend, inter alia, considering in the EIA screening stage whether the activity would cause substantive pollution, or significant and harmful changes to an area described as meeting the CBD ecologically or biologically significant marine area (EBSA) ${ }^{64}$ criteria or identified as a vulnerable marine ecosystem $(\mathrm{VME})^{65}$. It is further suggested that "any activity with the potential to cause substantial pollution of or significant and harmful changes should be subject to some form of

\footnotetext{
63 CBD decision XI/18 (2012). CBD, Marine and Coastal Biodiversity: Revised Voluntary Guidelines for the Consideration of Biodiversity in Environmental Impact Assessments and Strategic Environmental Assessments in Marine and Coastal Areas, Doc. UNEP/CBD/COP/11/23 (2012) [CBD EIA/SEA Guidelines].

${ }^{64}$ CBD Decision IX/20, Annex 1, adopts the EBSA criteria, and CBD Decision X/29 establishes the scientific and technical process for description of areas meeting the EBSA criteria.

${ }^{65}$ UNGA Resolution 61/105 (2006), para 83; FAO International Guidelines for the Management of Deep-sea Fisheries in the High Seas (FAO, 2009), para 42.
} 
initial screening and initial environmental evaluation." ${ }^{96}$ These Guidelines complement the FAO Deepsea Fisheries Guidelines, as it also covers activities other than bottom fishing.

In accordance with the Guidelines, Climate change and ocean acidification effects considerations should also be part of EIAs and SEAs, especially as part of cumulative impact assessments. ${ }^{67}$ This is particularly relevant for the achievement of the overdue Aichi Biodiversity Target $10^{68}$ and associated SDGs $14.2^{69}$ (ocean health, resilience and productivity) and $14.3^{70}$ (ocean acidification) by identifying and applying corresponding mitigation and adaptation measures in a way that minimises the impacts of anthropogenic pressures on ecosystems vulnerable to climate change and ocean acidification.

\section{Integrating Climate Change and Ocean Acidification effects into Marine Management}

In addition to the importance of incorporating climate change and ocean acidification effects into the EIA/SEA as per the CBD Guidelines, CBD COP has also developed priority actions for coral reefs and a workplan for cold water areas in an attempt to provide further guidance towards the achievement of Aichi Target 10. As noted above, actions taken by states and competent organisations towards the achievement of this target will also directly contribute to the achievement of SDGs 14.2 and 14.3, given the ultimate goal to increase marine ecosystems' resilience to better cope with the inevitable impacts from a changing climate and decreased $\mathrm{pH}$. Among other things, Parties were encouraged to "prioritize the enhancement of conservation and management measures for coral reefs and closely associated

\footnotetext{
${ }^{66}$ Ibid., para. 10 (b).

${ }^{67}$ CBD EIA/SEA Guidelines, para 31 (f).

68 "By 2015, the multiple anthropogenic pressures on coral reefs, and other vulnerable ecosystems impacted by climate change or ocean acidification are minimized, so as to maintain their integrity and functioning." (CBD Decision $\mathrm{X} / 2$, Target 10).

69 “By 2020, sustainably manage and protect marine and coastal ecosystems to avoid significant adverse impacts, including by strengthening their resilience, and take action for their restoration in order to achieve healthy and productive oceans" (SDG 14.2).

70 "Minimize and address the impacts of ocean acidification, including through enhanced scientific cooperation at all levels" (SDG 14.3).
} 
ecosystems" in areas described as EBSAs. ${ }^{71}$ Under the 2016 Voluntary Specific Workplan on Biodiversity in Cold-water Areas under the Jurisdictional Scope of the Convention, Parties were encouraged to identify and prioritise, as appropriate, for conservation, protection and management certain areas such as EBSAs, VMEs and Particularly Sensitive Sea Areas in cold-water areas. ${ }^{72}$ This policy recommendation is consistent with the findings of a recent scientific study on remaining global marine wilderness areas, which account for only about $13 \%$ of world's oceans. ${ }^{73}$ The authors argue that although climate change has been already affecting these wilderness areas, ensuring that other anthropogenic impacts are minimised will most likely contribute to the resilience of these areas, acting as climate refugia. ${ }^{74}$ EBSA descriptions that ranked high on the naturalness criterion should also be the object of attention in this regard.

\section{Area-based Management Tools, including marine protected areas (with respect to SDGs 14.5 and}

\section{2)}

Article 194(5) of UNCLOS establishes the obligation to protect and preserve rare or fragile ecosystems and habitats of depleted, threatened or endangered species as well as other forms of marine life. UNCLOS, however, does not provide criteria for identifying and managing such areas, including through area-based management tools (ABMTs), relying again on other instruments to do so. A vast array of ABMTs contribute to the achievement of a number of global targets, but the most commonly discussed among them are marine protected areas (MPAs) with respect to Aichi Biodiversity Target

\footnotetext{
${ }^{71}$ Priority Actions to Achieve Aichi Biodiversity Target 10 for Coral Reefs and Closely Associated Ecosystems, CBD decision XII/23 (2014), Annex, para 8.3.

${ }^{72}$ Voluntary Specific Workplan on Biodiversity in Cold-water Areas within the Jurisdictional Scope of the Convention: CBD decision XIII/11 (2016), Annex II, 5.3 (b).

${ }^{73}$ K Jones, CJ Klein, BS Halpern, O Venter, H Grantham, CD Kuempel, N Shumway, AM Friedlander, HP Possingham, JEM Watson, "The Location and Protection Status of Earth's Diminishing Marine Wilderness" (2018) 28 Current Biology 1-7. https://doi.org/10.1016/j.cub.2018.06.010

${ }^{74}$ Jones et al (2018). Ibid.
} 
$11^{75}$ and SDG 14.576; and other effective area-based conservation measures (OECMs) under Aichi Target 11. While achieving the numerical component of the target has been the primary focus of implementation to date, ${ }^{77}$ efforts have been made to provide CBD Parties with sufficient guidance to also implement the qualitative elements. ${ }^{78}$ Target 11 also makes reference to 'other effective area-based management measures' (OECMs) as working synergistically and contributing to a system of ecologically representative and well connected system of MPAs. The CBD is in the process of defining $\mathrm{OECMs}^{79}$ and approving implementation guidance.

The identification of areas important for biodiversity and ecosystem services (one of the qualitative elements of Aichi Target 11) has its legal foundation on Article 7 (a) of the CBD, which requires Parties to identify components of biodiversity important for conservation and sustainable use for the purposes of Articles 8 (in situ conservation) and 10 (sustainable use). The indicative list of natural categories of such areas contained in Annex I of the Convention closely resemble the EBSA criteria, which has been

\footnotetext{
75 "By 2020, at least 17 per cent of terrestrial and inland water, and 10 per cent of coastal and marine areas, especially areas of particular importance for biodiversity and ecosystem services, are conserved through effectively and equitably managed, ecologically representative and well connected systems of protected areas and other effective area-based conservation measures, and integrated into the wider landscapes and seascapes." (CBD Decision X/2, Aichi Target 11)
}

76 "By 2020, conserve at least 10 per cent of coastal and marine areas, consistent with national and international law and based on the best available scientific information" SDG 14.5. The Indicator for this target refers exclusively to the coverage of marine protected areas.

${ }^{77}$ D Diz, D Johnson, M Riddell, S Rees, J Battle, K Gjerde, S Hennige, JM Roberts, "Mainstreaming Marine Biodiversity into the SDGs: The role of other effective area-based conservation measures" (2018) 93 Marine Policy 251-261.

${ }^{78}$ Namely, areas important for biodiversity and ecosystem services; effective and equitable management; ecological representativity; connectivity; integration into the wider seascape. See S Rees, NL Foster, O Langmead, S Pittman, DE Johnson, "Defining the Qualitative Elements of Aichi Biodiversity Target 11 with Regard to the Marine and Coastal Environment in Order to Strengthen Global Efforts for Marine Biodiversity conservation outlined in the United Nations Sustainable Development Goal 14" (2018) 93 Marine Policy 241250 .

${ }^{79}$ The CBD twenty-second meeting of the Subsidiary Body on Scientific, Technical and Technological Advice (SBSTTA-22) adopted, and recommended COP to also adopt the following definition of OECM: "“'Other effective area-based conservation measure" means "a geographically defined area other than a Protected Area, which is governed and managed in ways that achieve positive and sustained long-term outcomes for the in situ conservation of biodiversity ${ }^{79}$ with associated ecosystem functions and services and, where applicable, cultural, spiritual, socioeconomic, and other locally relevant values"'. (CBD/SBSTTA/22/L.2, para 2). 
used to describe areas that meet the criteria globally through the CBD EBSA process initiated in 2010. Since its inception, 279 areas meeting the EBSA criteria have been described by COP up to COP 13 in 2016. In 2018, COP 14 will consider 42 additional areas meeting the EBSA criteria described in the CBD Secretariat facilitated Black Sea and Caspian Sea, and the Baltic Sea scientific and technical workshops. ${ }^{80}$ The description of EBSAs can contribute to not only Aichi Target 11 and SDG 14.5, but also Aichi Target 10 in the implementation of the Coldwater Areas Workplan and the Coral Reef Priority Actions and corresponding SDGs 14.2 and 14.3. EBSA description can also facilitate the implementation of CBD EIA/SEA Guidelines, as well as the CMS EIA Guidelines in modelling the effects of sound on CMS listed species and populations found in these EBSAs, and mitigating potential adverse effects. Furthermore, the description of such areas can also help sustainable fisheries management (Aichi Target 6, and SDG 14.4) through tailored measures such as gear modification, fisheries closures, bycatch preventive measure, among many others. ${ }^{81}$

With respect to ecological representativity of MPAs and OECMs, scientific criteria have been developed by COP 9, and include the following elements: EBSAs; representativity; connectivity; replication of ecological features; adequate and viable sites ${ }^{82}$ Guidance contained in Annex III of CBD Decision IX/20 (2008) on the four initial steps to be considered in the development of representative networks of MPAs is also of particular importance. These include the development of biogeographical classification systems for the pelagic and benthic realms, application of the precautionary approach when scientific information is not available, making use of qualitative and quantitative techniques to identify sites to be included in the network, and consideration of the size, shape, boundaries, buffer zones and management measures. Connectivity and ecological corridors have also been an object of attention of CMS ${ }^{83}$ Furthermore, Target 10 of the CMS Strategic Plan for Migratory Species 2015-

\footnotetext{
${ }^{80}$ CBD/EBSA/WS/2017/1/4 (2018); CBD/EBSA/WS/2018/1/4 (2018).

${ }^{81}$ D Diz, "Marine Biodiversity: Opportunities for Global Governance and Management Coherence" in M Solomon, T Markus (Eds.) Handbook on Marine Environment Protection (Springer 2018,) 855-870.

${ }^{82}$ CBD Decision IX/20 (2008), Annex II.

${ }^{83}$ See CMS Resolutions 12.7 (2017) and 12.26 (2017).
} 
2013 states that "all critical habitats and sites for migratory species are identified and included in areabased conservation measures, so as to maintain their quality, integrity, resilience and functioning in accordance with the implantation of Aichi Target 11", ${ }^{84}$ thus, reinforcing the complementary efforts between these two Conventions. Therefore, the implementation of SDG 14.5 (marine protected areas) can be more effectively (and efficiently) achieved, if these qualitative elements from biodiversityrelated conventions are observed. For areas beyond national jurisdiction, enhanced governance coherence is expected to be achieved through a new legally binding instrument under UNCLOS, currently under negotiation..$^{85}$

As for the integration of such well-connected and well-managed representative system of MPAs and OECMs into a broader seascape, Diz et al (2018) argues that such integration can be best achieved through marine spatial planning. ${ }^{86}$

The CBD parties have acknowledged marine spatial planning (MSP) as a participatory tool for the implementation of the ecosystem approach. ${ }^{87}$ In this connection, MSP has also been perceived to be the appropriate tool to enable integration of area-based management tools into a wider seascape, as per CBD Aichi Biodiversity Target $11{ }^{88}$ MSP has also been considered an integrative tool to enhance

\footnotetext{
${ }^{84}$ CMS Resolution 11.2, Annex 1 (2014).

${ }^{85}$ UNGA Resolution 72/249 (2017).

${ }^{86}$ Diz et al (2018)

${ }^{87}$ CBD Decision XIII/9 (2016).

${ }^{88}$ D Diz, D Johnson, M Riddell, S Rees, J Battle, K Gjerde, S Hennige, JM Roberts, "Mainstreaming Marine Biodiversity into the SDGs: The role of other effective area-based conservation measures" (2018) 93 Marine Policy 251-261.
} 
synergies between SDG 14 and other SDGs in different scales. ${ }^{89}$ On the high seas, MSP can be used as a tool to give effect the States obligation of due regard to competing activities in a given area. ${ }^{90}$

\section{CONCLUSIONS}

The implementation of SDG 14 targets can be facilitated by the application of the ecosystem approach and the respective integration of biodiversity-related standards, guidance, goals and targets agreed by the international community in different fora. This paper mostly focused on the co-relation between SDGs 14.c on the role of UNCLOS and 14.1 - 14.5 with specific CBD Decisions, CMS Resolutions, and relevant FAO instruments. The legal basis for this strong relationship can be found on a number of UNCLOS provisions which incorporates by reference global, regional or sub-regional minimum standards for the establishment of conservation and management measures concerning fisheries and marine pollution in a broad sense.

Furthermore, UNCLOS also provide for the protection of important marine habitats, but does not elaborate on how to identify these sites and how to protect them. Considering that all UNCLOS Parties are also Parties to the CBD, and given the relationship between the two Conventions, it has been argued that the standards and guidance developed by the CBD concerning ecologically representative MPA systems and effective and equitable management provide sound guidance for the implementation of SDG 14.5. The incorporation of guidance and recommendations provided by CMS on ecological corridors and connectivity should also be observed in this context as it complements the work of the $\mathrm{CBD}$ and therefore, contribute to governance coherence.

The overarching frame for the actions taken in response of these global targets should be the ecosystem approach, which has found wide support in international instruments. The ecosystem approach, which

\footnotetext{
${ }^{89}$ M Ntona, E Morgera, "Connecting SDG 14 with the other Sustainable Development Goals through Marine Spatial Planning” (2018) 93 Marine Policy 214-222.

${ }^{90}$ D Owen, "Principles and Objectives of the Legal Regime Governing Areas beyond National Jurisdiction Commentary on Tullio Treves" in EJ Molennar and AG Oude Elferink (eds) The Internaitonal Legal Regime of Areas beyond National Jurisdiction: Current and Future Developments (Martinus Nijhoff Publishers, 2010).
} 
is not entirely ecocentric, nor anthropocentric, recognizes that humans are part of the ecosystem and therefore the objective of management is a societal choice, while acknowledging that ecosystems must be managed within the limits of their functioning. ${ }^{91}$ To ensure that this balance is achieved in the context of sustainable development, the instruments, guidelines and processes referred herein play a significant role in the full implementation of the ecosystem approach. For instance, the EBSA process established under the auspices of the $\mathrm{CBD}$, can contribute to essential scientific information for the adoption by Coastal States and competent organisations of appropriate conservation and management measures, including ABMTs and EIAs, and therefore contributing to at least Aichi Targets 6, 10 and 11, CMS Target 10, SDG targets 14.1, 14.2, 14.4, 14.3, and 14.5.

Nevertheless, despite ample guidance, implementation challenges are multiple, ranging from lack of capacity or resources to insufficient coordination of efforts among ministries and across different fora. Insufficient coordination, collaboration and even oversight of implementation is prominent in areas beyond national jurisdiction. For this reason, a new agreement under UNCLOS is being negotiated for the conservation and sustainable use of biodiversity of areas beyond national jurisdiction. The four main elements of the agreement include ABMTs, including MPAs, EIAs, marine genetic resources and capacity building and technology transfer. If SDG 14 is to be achieved with respect to areas beyond national jurisdiction, the incorporation of the ecosystem approach into the agreement, along with all of these minimum standards and guidance developed by a diverse range of international bodies is essential, along with a system for enhanced cooperation, coordination and implementation oversight.

\footnotetext{
${ }^{91}$ CBD Decisions V/6 (2000) and VII/11 (2004).
} 